\title{
Age-period-cohort Analysis of Healthy Lifestyle Behaviors Using the National Health and Nutrition Survey in Japan
}

\author{
Tasuku Okui \\ Medical Information Center, Kyushu University Hospital, Fukuoka, Japan
}

Objectives: This study conducted an age-period-cohort (APC) analysis of trends in healthy lifestyle behaviors in Japan.

Methods: We used National Health and Nutrition Survey data on salt intake and prevalence of smoking, drinking, and physical activity between 1995 and 2018 in Japan. Age groups were defined from 20 years to 69 years old in 10-year increments. Cohorts were defined for each age group of each year with a 1-year shift, and cohorts born in 1926-1935 (first cohort) until 1989-1998 (last cohort) were examined. We conducted a Bayesian APC analysis, calculating estimated values for each behavior by age group, period, and cohort.

Results: Estimated salt intake decreased from cohorts born in the 1930s to the 1960s, but increased thereafter in both genders, and the magnitude of increase was larger for men. Estimated smoking prevalence increased in the cohorts starting from the 1930s for men and the 1940s for women, and then decreased starting in the cohorts born in the 1970s for both genders. Although estimated drinking prevalence decreased starting in the cohorts born in approximately 1960 for men, for women it increased until the cohorts born in approximately 1970. Estimated physical activity prevalence decreased starting in the cohorts born in the 1940s in both genders, but the magnitude of decrease was larger for women.

Conclusions: Trends in cohort effects differed by gender, which might be related to changes in the social environment for women. Improvements in dietary and exercise habits are required in more recently born cohorts of both genders.

Key words: Cohort effect, Life style, Smoking, Alcohol drinking, Japan

\section{INTRODUCTION}

The increase in the number of patients with lifestyle-related diseases is a major concern in Japan, as that of major diseases such as cancer, cardiovascular diseases (CVD), diabetes, and dyslipidemia in Japan has consistently increased over the years [1]. According to the Patient Survey in Japan [1], the esti-

Received: April 26, 2020 Accepted: July 31, 2020

Corresponding author: Tasuku Okui, PhD

Medical Information Center, Kyushu University Hospital, Maidashi

3-1-1 Higashi-ku, Fukuoka 812-8582, Japan

E-mail: task10300@gmail.com

This is an Open Access article distributed under the terms of the Creative Commons Attribution Non-Commercial License (https://creativecommons.org/licenses/bync/4.0// which permits unrestricted non-commercial use, distribution, and reproduction in any medium, provided the original work is properly cited. mated number of cancer patients increased from 1.26 million in 1999 to 1.73 million in 2017. In addition, the estimated number of patients with CVD increased from 10.87 million in 1999 to 13.01 million in 2017. As a result, national medical expenses have continued to rise; according to national medical expenses data [2], the expenses for CVDs amounted to 6.08 trillion yen in 2017, those for cancer amounted to 3.82 trillion yen, and those for endocrine and metabolic diseases like diabetes amounted to 2.09 trillion yen. Therefore, better prevention of lifestyle-related diseases is required in Japan.

Dietary habits, smoking, drinking, and physical activity (PA) are often pointed out as lifestyle choices that trigger lifestylerelated diseases [3-5]. Among dietary habits, fat and salt intake are often considered as risk factors for CVDs or dyslipidemia $[6,7]$. The association between these lifestyle factors and 
disease has been clearly demonstrated in many studies. It is also important, though, to investigate changes in lifestyle behaviors. Salt intake and the prevalence of smoking have decreased over the past 10 years among both men and women [8]. Conversely, the prevalence of alcohol drinking (hereafter referred to as drinking prevalence) has remained stable among men and has been increasing among women [8]. Although step counts have generally remained stable for both men and women [8], a previous report indicated that average step counts decreased between before 2000 and 2010 for both men and women [9]. Although studies have analyzed changes in lifestyle behaviors, analyses focusing on cohort effects on lifestyle behaviors are still rare in Japan, and changes in lifestyle behaviors among cohorts are uncertain.

Age-period-cohort (APC) analysis is often used as a method of decomposing statistics into age, period, and cohort effects [10]. APC analysis has been used to analyze trends in cancer and cardiovascular mortality in Japan [11,12], and reasons for changes in cohort effects on diseases have been discussed, taking into account lifestyle changes among cohorts. In order to interpret the results of these studies estimating cohort effects on lifestyle-related diseases, it is also meaningful to conduct APC analyses for disease risk factors. Changes among cohorts in the energy intake ratio from each type of nutrient have previously been investigated using APC analysis in Japan [13]. However, APC analyses of cohort effects on salt intake and/or the prevalence of smoking, drinking, and PA have not yet been conducted. Therefore, in this study, we conducted an APC analysis of lifestyle behavior trends.

\section{METHODS}

We used data from the National Health and Nutrition Survey in Japan $[14,15]$. This survey is conducted every year to obtain detailed information on the physical status, nutritional intake, and lifestyles of Japanese people [8]. Subjects are chosen by stratified random sampling from all households in Japan. Subjects are asked by questionnaire about their physical conditions, including height and weight, nutrient intake, and lifestyle information including PA and sleep. The questionnaire about nutrient intake measures levels of consumption of various nutritional sources, including total energy, protein, fat, cholesterol, carbohydrate, dietary fiber, vitamin, salt, potassium, and calcium $[14,15]$. We analyzed data on salt intake, smoking prevalence, drinking prevalence, and the prevalence of PA (hereafter referred to as PA prevalence) by age group and gender between 1995 and 2018. Smoking prevalence and drinking prevalence were defined, respectively, the rate of persons who habitually smoked or drank at a given time. PA prevalence was defined as the proportion of subjects who exercised for more than 30 minutes at a time, at least twice per week, and who continued this habit for more than 1 year. Salt intake was defined as the mean intake of salt per day. Since salt intake is known to be affected by total energy intake, we analyzed mean salt intake (g) per $1000 \mathrm{kcal}$ [16]. Drinking prevalence was not measured in 2013. Age groups were defined using 10-year increments from 20-29 years to 60-69 years. Those who were $60-69$ years old in 1995 (i.e., those born between 1926 and 1935) were the first cohort, as they were the oldest birth cohort in the data set. Through a 1-year shift of birth years, starting from the first cohort, the age group of participants who were 20-29 years old in 2018 (i.e., those born between 1989 and 1998) comprised the last cohort.

First, we calculated birth cohort-specific salt intake, smoking prevalence, drinking prevalence, and PA prevalence by age group for men and women to describe cohort effects. We also calculated age-adjusted rates or amounts of the lifestyle behaviors. Age-adjusted rates or amounts of lifestyle behaviors were calculated using the direct method [17], and the total population in 1995 was used as the standard population for both men and women. Data from Vital Statistics in Japan [18] were used for population ratios. We then used a Bayesian APC model. To analyze salt intake, we used a Bayesian APC model that assumed that salt intake values followed a normal distribution whose mean was an additive model of APC effects, similar to the model used by Kwok et al. [19]. Let $y_{i j}$ be the salt intake for the age group $i(1, \ldots, I)$ in year $j(1, \ldots, J)$. In the mod$\mathrm{el}$, salt intake is assumed to follow the normal distribution shown below, whose mean is $\lambda_{i j}$,

$$
\begin{gathered}
y_{i j} \sim \operatorname{Normal}\left(\lambda_{i j}, \sigma^{2}\right), \\
\lambda_{i j}=\delta+\alpha_{i}+\beta_{j}+\gamma_{k}
\end{gathered}
$$

Where $\delta$ is the intercept, $\alpha_{i}$ is the age group effect, $\beta_{j}$ is the period effect, $\gamma_{k}(k=1, \ldots, K)$ is the cohort effect, and $\sigma^{2}$ is the variance of $y_{i j} . I, J$, and $K$ are the number of time points for age groups, periods, and cohorts, respectively. To identify each parameter, the sum of each effect was restricted to zero, and a first-order random-walk was used as a prior for each effect [20]. Because smoking prevalence, drinking prevalence, and 

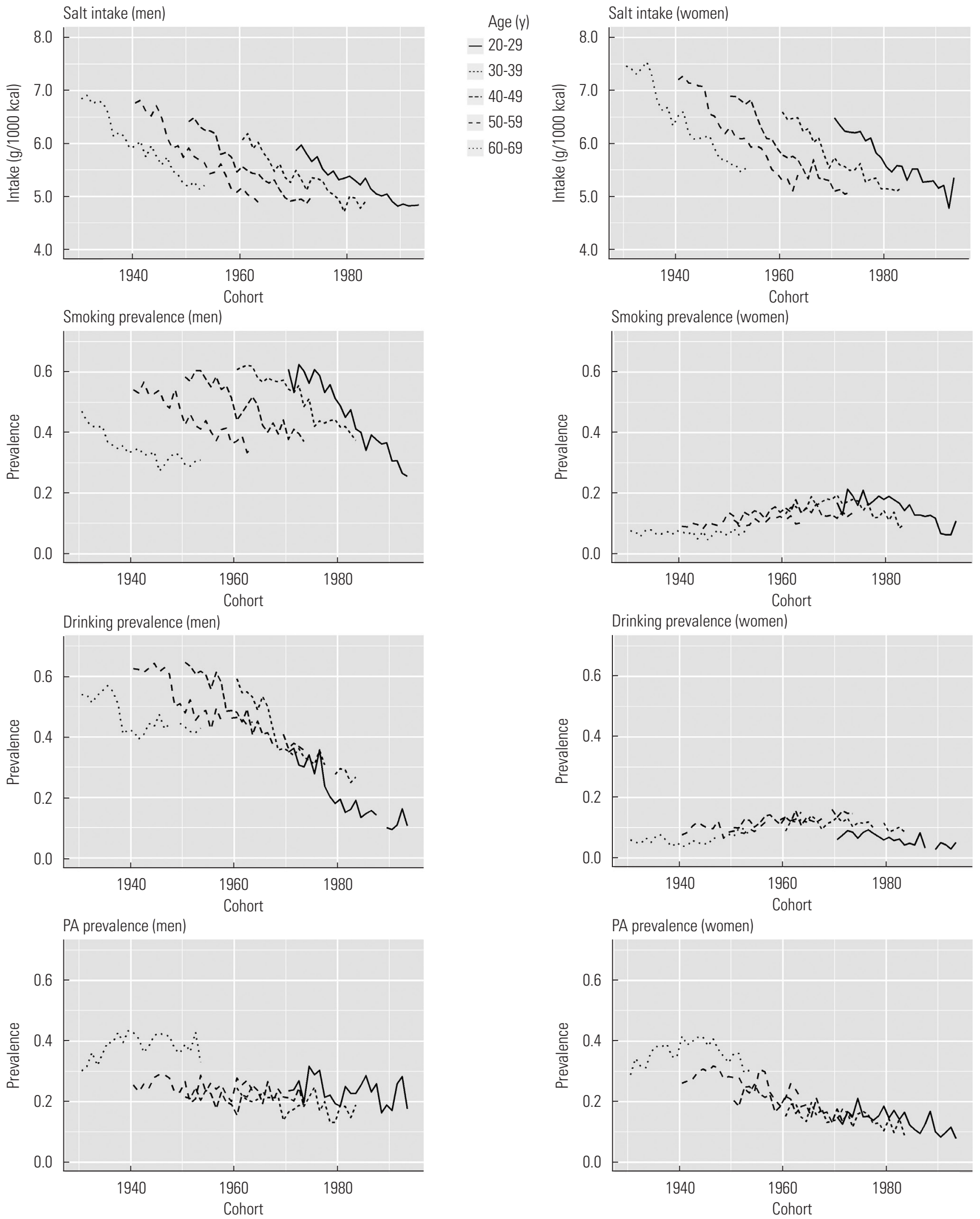

Figure 1. Birth cohort-specific salt intake, smoking prevalence, drinking prevalence, and physical activity (PA) prevalence by age groups for both men and women. 
PA prevalence were all proportion data, to analyze these we used a Bayesian APC model that assumed that the log odds of each prevalence, $\eta_{i j}=\log \left(y_{i j} /\left[1-y_{i j}\right]\right)$, followed a normal distribution whose mean was an additive model of APC effects. The estimated prevalence or amount of each lifestyle behavior was then calculated for each age group, period, and cohort using the estimated parameters. For example, the estimated prevalence for age group $i$ can be calculated as expit $\left(\hat{\delta}+\hat{\alpha}_{i}\right)$, where $\hat{\delta}$ and $\hat{\alpha}_{i}$ are the estimated values for the intercept $\delta$ and the age effect $\alpha_{i}$, and expit is the sigmoid function.

We investigated the increase or decrease of estimated effects based on the effect estimates, as is usually done in APC analyses [11-13,21,22]. All statistical analyses were conducted using $\mathrm{R}$ version 3.5.1 (https://cran.r-project.org/bin/windows/ base/old/3.5.1/), and the Hamiltonian Monte Carlo method was used to estimate the parameters of the APC model [23].

\section{Ethics Statement}

This study did not require ethical approval because it used public data.

\section{RESULTS}

Figure 1 shows results for birth cohort-specific salt intake, smoking prevalence, drinking prevalence, and PA prevalence by age group for men and women. Salt intake decreased across cohorts in all age groups for men and women. Although smoking prevalence decreased in all age groups across cohorts for men, smoking prevalence did not decrease in women who were $40-69$ years of age. Although drinking prevalence in all age groups decreased for men, the trends differed across age groups for women. Although PA prevalence remained relatively stable across 20-59 years of age in men, it showed de-

Table 1. Yearly age-adjusted salt intake, smoking prevalence, drinking prevalence, and physical activity (PA) prevalence from 1995 to 2018

\begin{tabular}{|c|c|c|c|c|c|c|c|c|}
\hline \multirow[b]{2}{*}{ Year } & \multicolumn{4}{|c|}{ Men } & \multicolumn{4}{|c|}{ Women } \\
\hline & Salt intake ${ }^{1}$ & $\begin{array}{c}\text { Smoking } \\
\text { prevalence }\end{array}$ & $\begin{array}{c}\text { Drinking } \\
\text { prevalence }\end{array}$ & $\begin{array}{c}\text { PA } \\
\text { prevalence }\end{array}$ & Salt intake ${ }^{1}$ & $\begin{array}{c}\text { Smoking } \\
\text { prevalence }\end{array}$ & $\begin{array}{c}\text { Drinking } \\
\text { prevalence }\end{array}$ & $\begin{array}{c}\text { PA } \\
\text { prevalence }\end{array}$ \\
\hline 1995 & 6.4 & 56.7 & 54.9 & 24.7 & 6.9 & 11.8 & 7.8 & 20.7 \\
\hline 1996 & 6.5 & 54.1 & 54.0 & 24.0 & 6.9 & 10.9 & 8.7 & 21.6 \\
\hline 1997 & 6.3 & 57.5 & 51.6 & 26.5 & 6.8 & 13.7 & 10.0 & 23.5 \\
\hline 1998 & 6.2 & 56.0 & 52.0 & 22.9 & 6.8 & 12.9 & 10.6 & 22.4 \\
\hline 1999 & 6.2 & 53.9 & 52.4 & 27.7 & 6.7 & 12.5 & 9.0 & 25.2 \\
\hline 2000 & 6.1 & 53.5 & 50.5 & 28.1 & 6.7 & 14.4 & 10.3 & 24.5 \\
\hline 2001 & 5.8 & 53.0 & 52.9 & 27.0 & 6.3 & 12.2 & 10.8 & 23.7 \\
\hline 2002 & 5.8 & 50.1 & 47.0 & 26.6 & 6.3 & 13.4 & 10.2 & 24.1 \\
\hline 2003 & 5.7 & 52.3 & 39.0 & 24.5 & 6.1 & 14.3 & 8.5 & 20.9 \\
\hline 2004 & 5.5 & 48.8 & 39.1 & 23.0 & 5.9 & 14.4 & 8.6 & 22.2 \\
\hline 2005 & 5.6 & 45.1 & 38.4 & 23.1 & 6.0 & 14.9 & 9.5 & 23.3 \\
\hline 2006 & 5.6 & 45.5 & 36.9 & 24.4 & 5.9 & 13.0 & 8.6 & 23.8 \\
\hline 2007 & 5.4 & 45.9 & 37.4 & 23.6 & 5.8 & 14.1 & 10.1 & 21.3 \\
\hline 2008 & 5.5 & 43.6 & 36.6 & 26.3 & 5.8 & 12.3 & 8.1 & 21.8 \\
\hline 2009 & 5.4 & 44.0 & 36.3 & 26.6 & 5.6 & 13.9 & 8.8 & 21.5 \\
\hline 2010 & 5.3 & 37.7 & 34.7 & 27.6 & 5.7 & 11.4 & 8.7 & 21.4 \\
\hline 2011 & 5.3 & 38.3 & 36.5 & 26.1 & 5.7 & 12.8 & 10.2 & 22.6 \\
\hline 2012 & 5.2 & 39.7 & 33.8 & 26.0 & 5.5 & 11.5 & 8.8 & 19.5 \\
\hline 2013 & 5.1 & 39.0 & - & 22.1 & 5.4 & 11.3 & - & 19.8 \\
\hline 2014 & 4.9 & 39.1 & 33.3 & 21.5 & 5.4 & 11.7 & 10.3 & 16.3 \\
\hline 2015 & 5.0 & 35.5 & 32.3 & 24.1 & 5.2 & 9.8 & 9.7 & 18.7 \\
\hline 2016 & 5.0 & 36.6 & 32.6 & 24.9 & 5.3 & 10.7 & 10.4 & 18.2 \\
\hline 2017 & 4.9 & 34.1 & 32.2 & 27.0 & 5.1 & 9.0 & 10.1 & 18.6 \\
\hline 2018 & 5.0 & 33.2 & 31.6 & 21.7 & 5.3 & 10.6 & 10.4 & 16.0 \\
\hline
\end{tabular}

Values are presented as percentage.

'Unit: g/1000 kcal. 


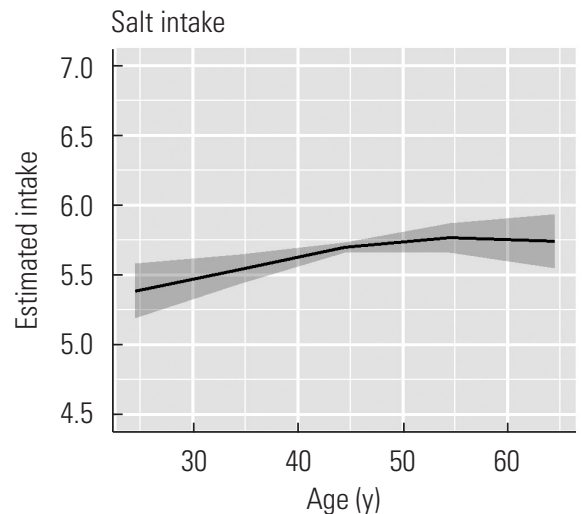

Smoking prevalence

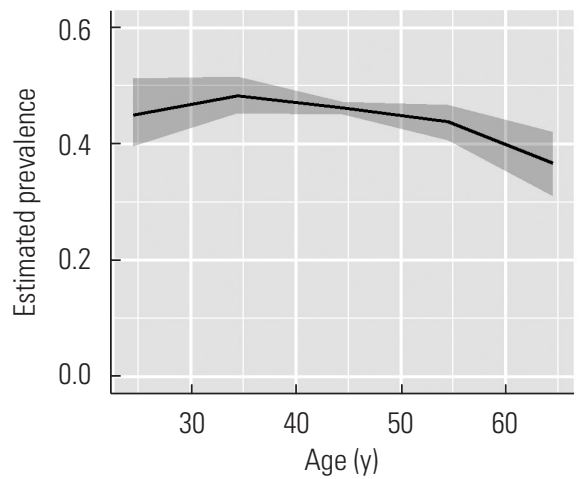

Drinking prevalence

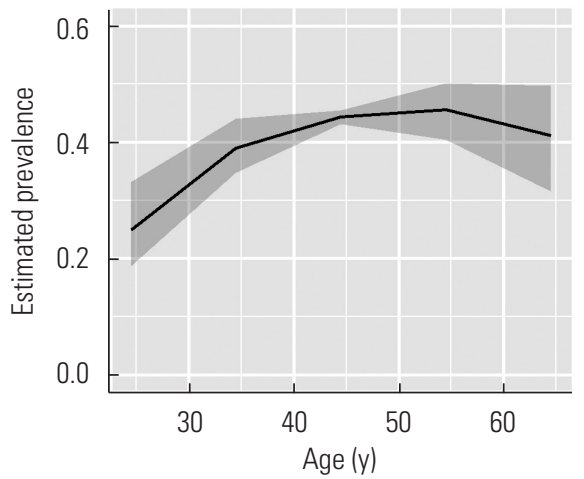

PA prevalence

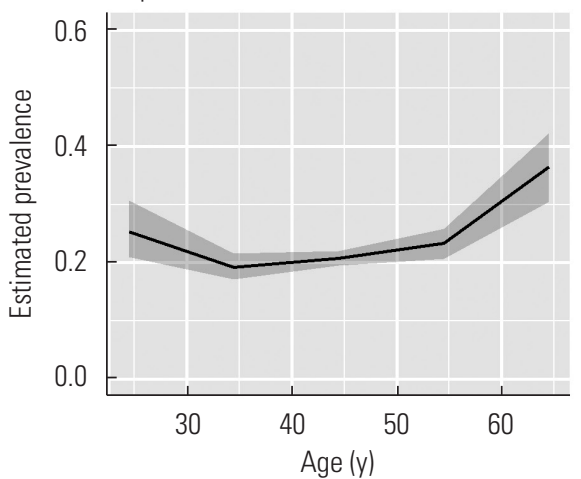

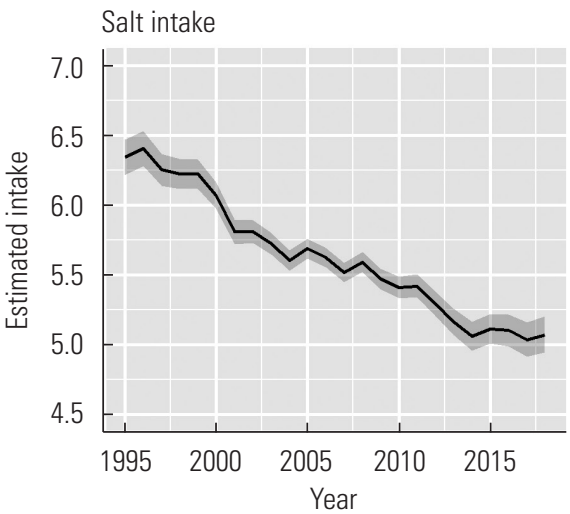

Smoking prevalence

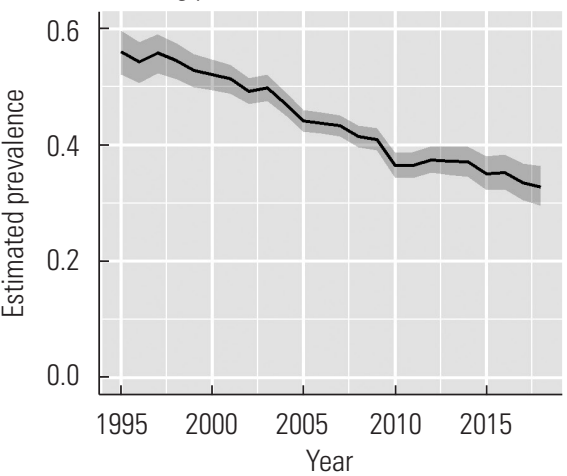

Drinking prevalence

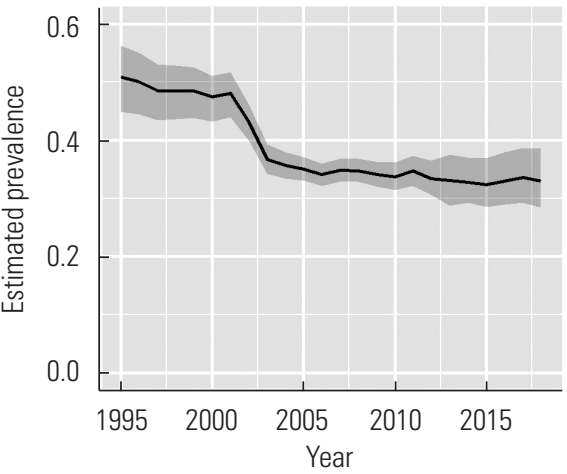

PA prevalence

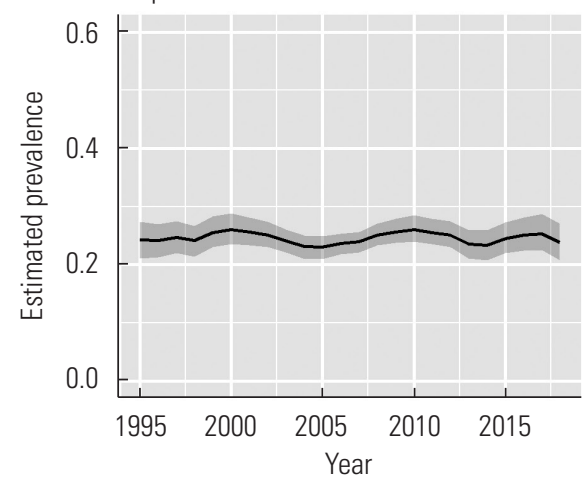

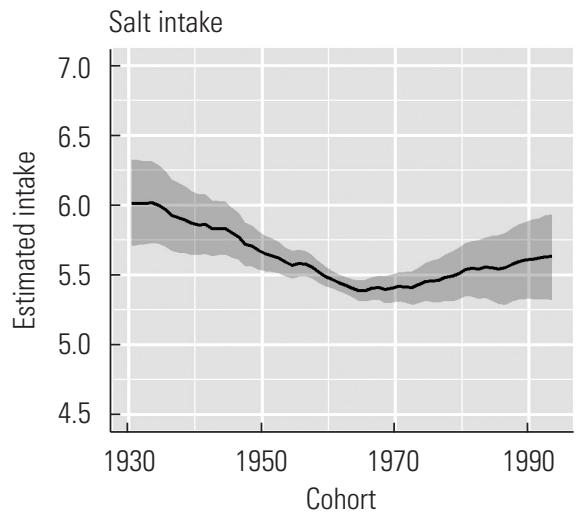

Smoking prevalence

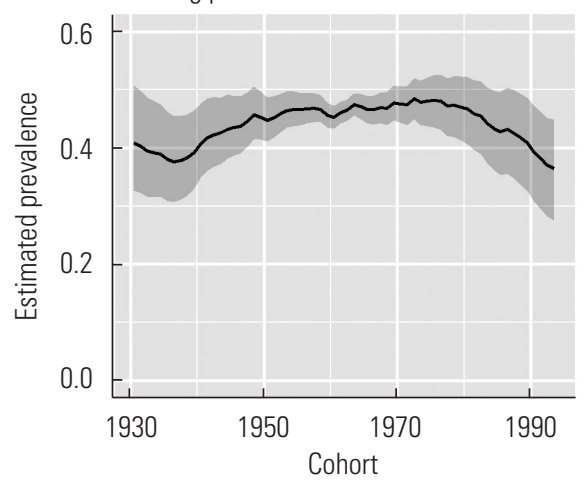

Drinking prevalence

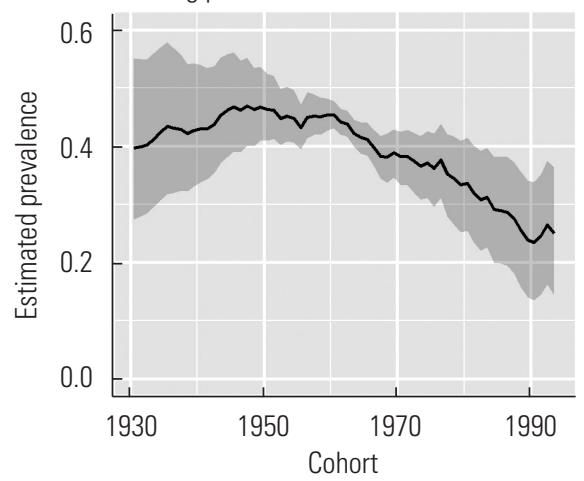

PA prevalence

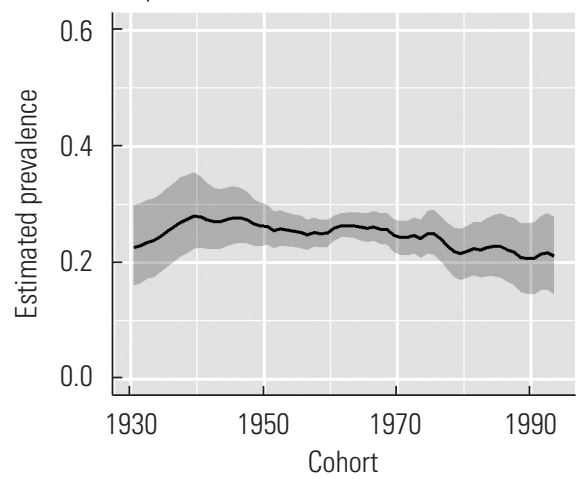

Figure 2. Results of age-period-cohort analysis of salt intake (unit: $\mathrm{g} / 1000 \mathrm{kcal}$ ), smoking prevalence, drinking prevalence, and physical activity (PA) prevalence for men. Solid lines signify estimates of each effect, and the shadings show $95 \%$ credible intervals of each effect. 


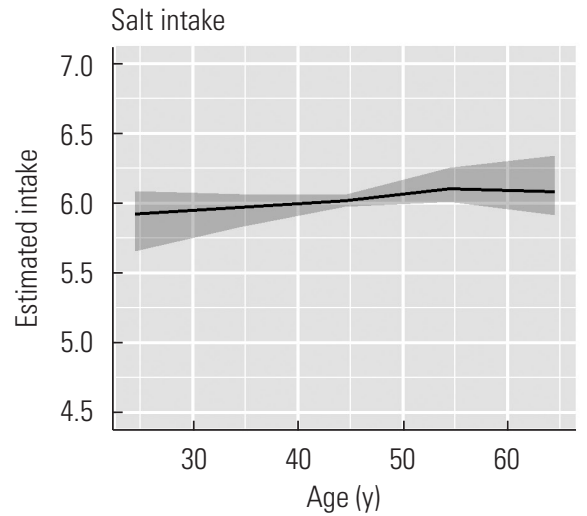

Smoking prevalence
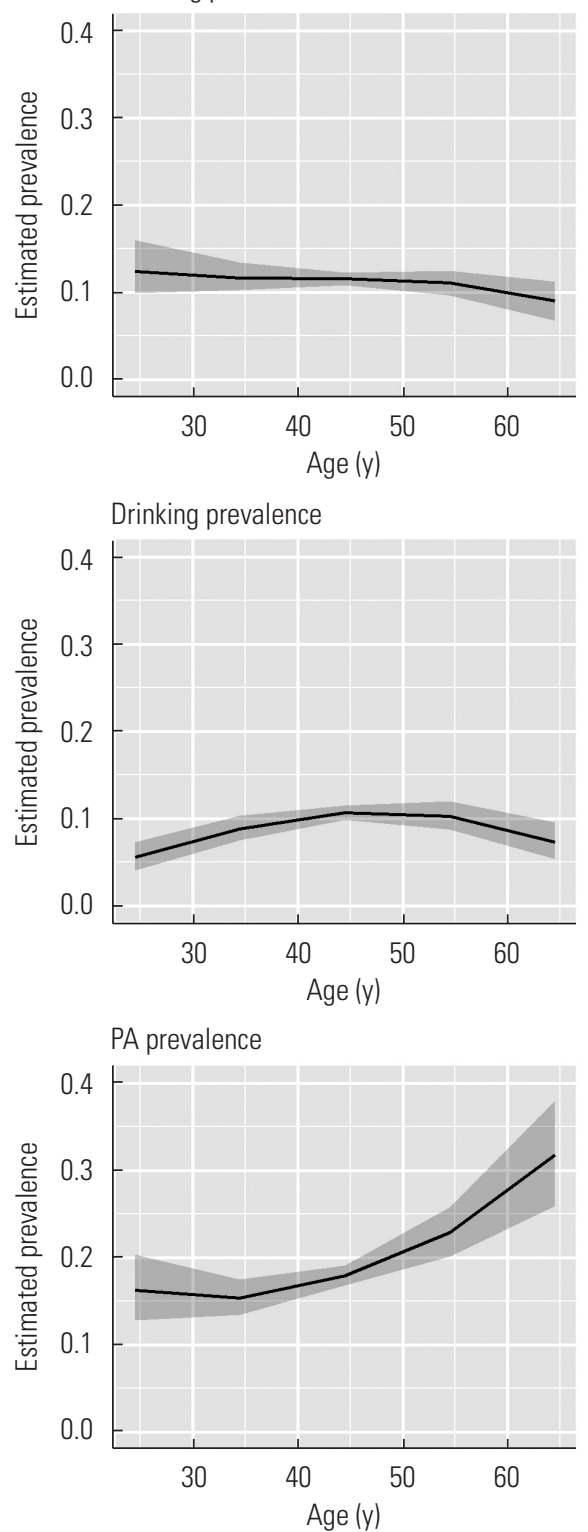

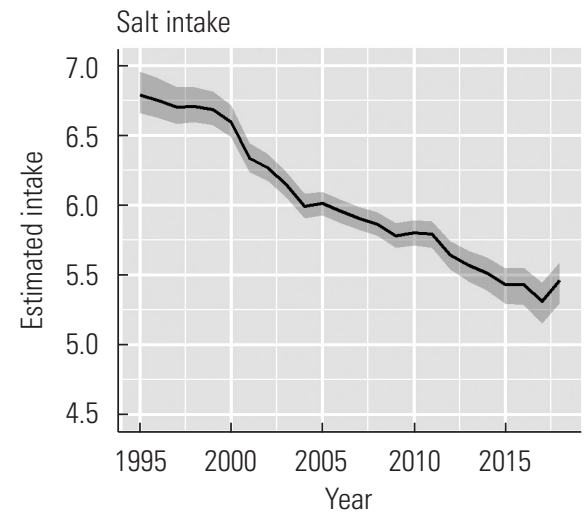

Smoking prevalence

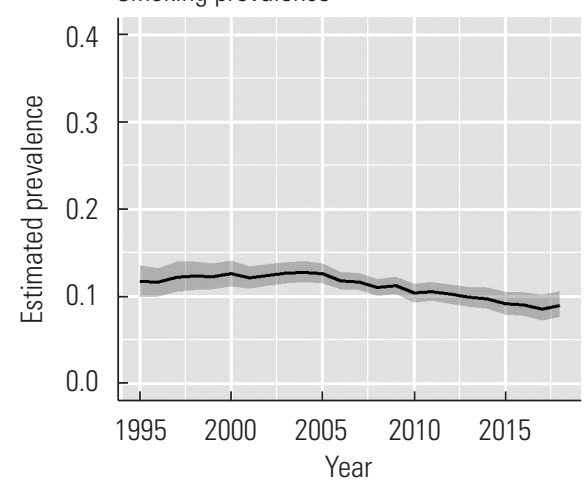

Drinking prevalence

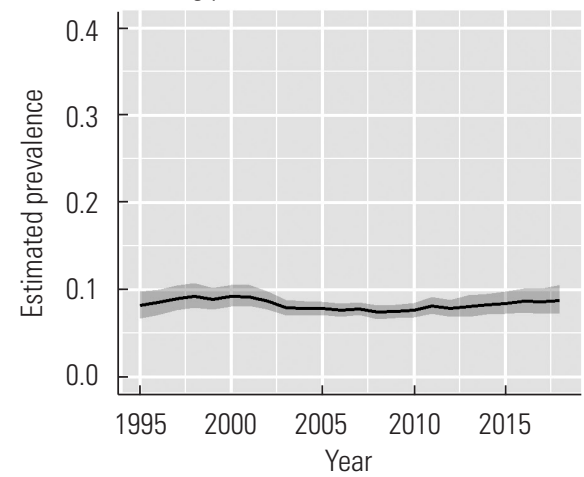

PA prevalence

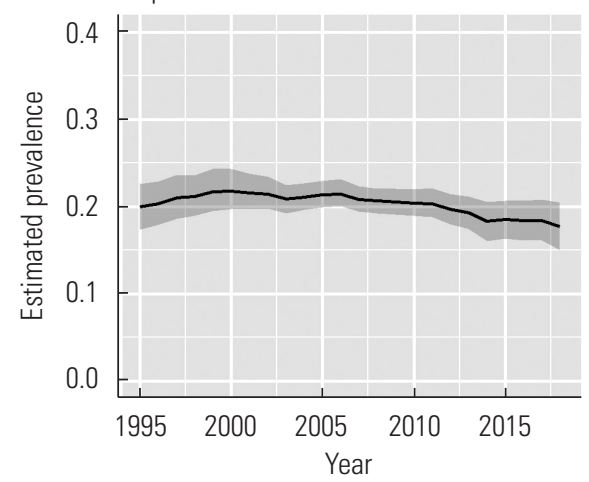

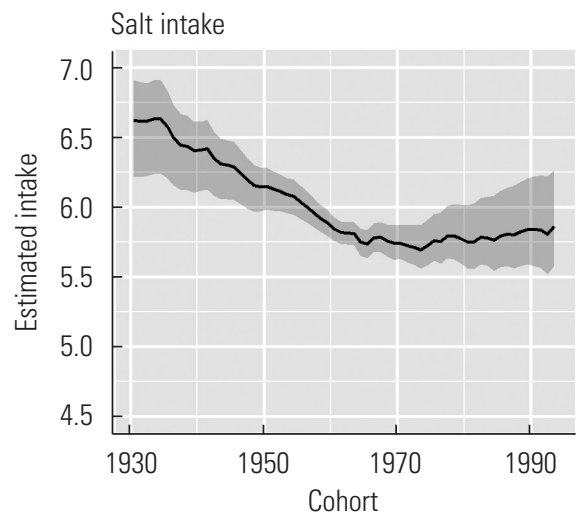

Smoking prevalence
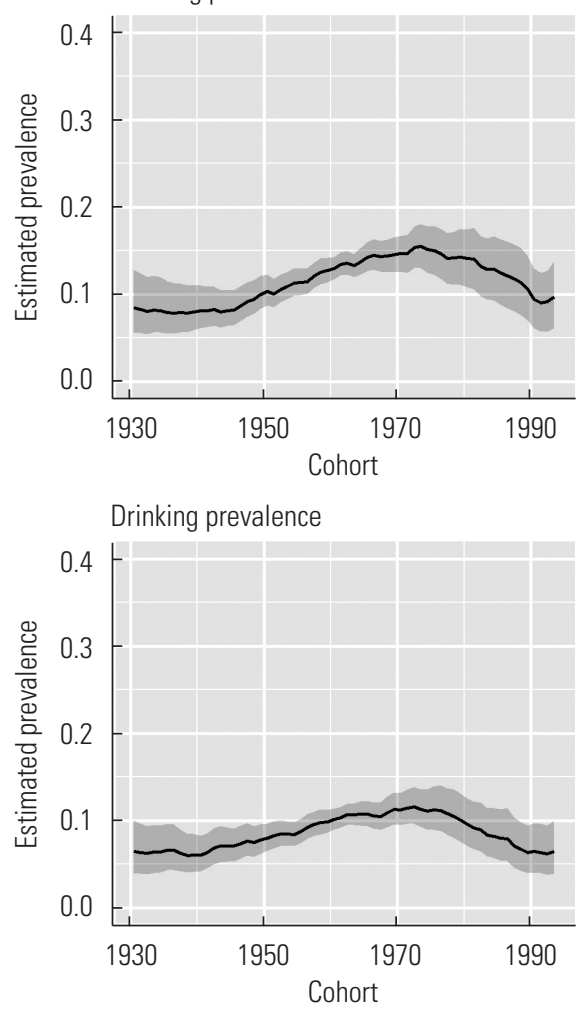

PA prevalence

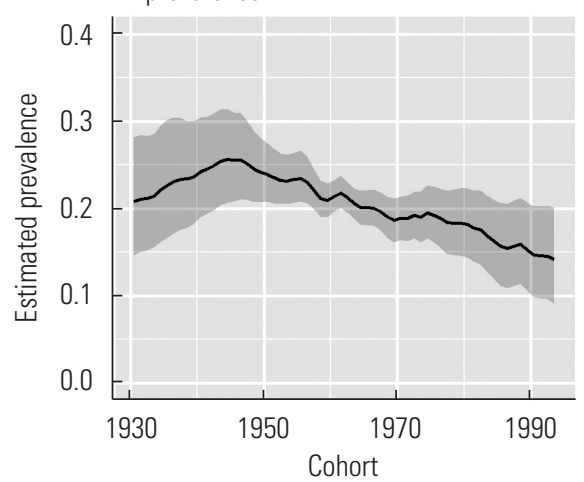

Figure 3. Results of age-period-cohort analysis of salt intake (unit: $\mathrm{g} / 1000 \mathrm{kcal}$ ), smoking prevalence, drinking prevalence, and physical activity (PA) prevalence for women. Solid lines signify estimates of each effect, and the shadings show $95 \%$ credible intervals of each effect. 
creasing trends in some age groups for women.

Table 1 shows yearly age-adjusted salt intake, smoking prevalence, drinking prevalence, and PA prevalence from 1995 to 2018. Age-adjusted salt intake decreased throughout the study period for both men and women. Age-adjusted smoking prevalence decreased throughout the study period for men, and for women, it showed a decreasing trend starting in approximately 2005 . Although age-adjusted drinking prevalence decreased throughout the study period for men, for women it remained relatively stable. Age-adjusted PA prevalence continued to fluctuate for both men and women, and it decreased in recent years for women.

Figure 2 shows results of the APC analysis of salt intake, smoking prevalence, drinking prevalence, and PA prevalence for men. Estimated salt intake increased until 50-59 years old, and it decreased throughout the study period. In addition, the estimated salt intake decreased by approximately $0.6 \mathrm{~g}$ in the cohorts born between approximately 1930 and the mid-1960s, and it increased by approximately $0.3 \mathrm{~g}$ in the cohorts born in roughly 1990. Estimated smoking prevalence decreased both throughout the study period and with increasing age. In addition, estimated smoking prevalence increased from approximately 0.37 to 0.48 in the cohorts born between the mid-1930s and the late 1970s and began to decrease thereafter. The peak estimated drinking prevalence was at 40-59 years old. Estimated drinking prevalence decreased in the early 2000s, and showed a slight decreasing trend thereafter. In addition, estimated drinking prevalence began to decrease starting in the cohorts born in approximately 1960, and it decreased from approximately 0.45 to 0.23 in the cohorts born between approximately 1960 and 1990. Estimated PA prevalence began to increase starting in the age groups of 30-39 years, and showed a stable trend over the years. In addition, estimated PA prevalence increased until the cohorts born in approximately 1940, and showed slight decreasing trend thereafter. It decreased from 0.28 to 0.21 in the cohorts born between approximately 1940 and 1990.

Figure 3 shows the results of the APC analysis of salt intake, smoking prevalence, drinking prevalence, and PA prevalence for women. Peak estimated salt intake was found at 50-69 years old, and it decreased throughout the study period, similar to results observed in men. In addition, estimated salt intake decreased by approximately $0.9 \mathrm{~g}$ in the cohorts born between the 1930s and the mid-1970s, and slightly increased thereafter. Estimated smoking prevalence decreased in older age groups, and it started to decrease in 2005. In addition, the estimated smoking prevalence increased from approximately 0.08 to 0.15 in the cohorts born between the 1940s and the mid-1970s and decreased to approximately 0.10 in the cohorts born in approximately 1990. The peak estimated drinking prevalence was found at 40-49 years old. Estimated drinking prevalence also remained relatively stable over the years, although it slightly increased in recent years. In addition, estimated drinking prevalence increased from 0.06 to 0.11 in the cohorts born between approximately 1940 and the mid1970s, and decreased thereafter. Estimated PA prevalence tended to increase with increasing age, and slightly decreased starting in approximately 2000. In addition, estimated PA prevalence increased until cohorts born in the mid-1940s, and decreased thereafter. It decreased from approximately 0.25 to 0.14 in the cohorts born between the 1940s and approximately 1990.

\section{DISCUSSION}

The trends in cohort effects on salt intake were similar in both genders. A decrease in salt intake was observed in both genders in cohorts born in the 1930s-1960s. It has been shown that systolic blood pressure continued to decrease between 1960 and 1990 in Japan [24], and decreased salt intake across periods and cohorts is thought to be related to this result. However, our results suggest that salt intake is increasing in more recently born cohorts for both men and women, particularly for men.

Regarding cohort effects on smoking prevalence, estimated smoking prevalence increased in the cohorts born from approximately the 1930s to the 1970s and began to decrease thereafter for men. It is known that smoking prevalence among Japanese people began to decrease from approximately the late 1960s onwards [25], and it is suggested that decrease of the cohort effect occurred later than the overall decrease in smoking prevalence. The cohort effect on heart disease mortality showed a decrease starting in cohorts born in approximately 1970 for men [26], which might be related to the cohort effect of decreasing smoking prevalence. In contrast, estimated smoking prevalence for women increased until the cohorts born in the mid-1970s. The rate of the decrease of smoking prevalence for women was smaller than that for men [25], which is considered to be related to the obvious increase of smoking prevalence over the cohorts among wom- 
en. According to an epidemiological study investigating smoking status and socioeconomic factors in Japan [27], being employed was strongly associated with smoking in women than in men. Therefore, the increase in the employment rate of women across cohorts might be related to their increased smoking prevalence.

Regarding cohort effects on drinking prevalence, a difference was observed in the turning point between men and women. Although estimated drinking prevalence for men began to decrease starting in the cohorts born in approximately 1960, for women the decrease started in the cohorts born in approximately 1970 . The trend in the cohort effect on drinking prevalence was similar to that of smoking prevalence in women. As shown in Table 1, age-adjusted drinking prevalence increased among women, unlike men, in recent years, and the difference in these trends is considered to contribute to the results of ageadjusted drinking prevalence. Although the underlying reason for this difference is uncertain, it might be related to changes in the social environment of women among cohorts, as previous studies $[28,29]$ have shown associations between employment status and drinking in other countries. Japanese people often consume alcohol in order to form friendly relationships with others [30], which is thought to be related to employment status. Therefore, a study investigating predictors of drinking behavior in Japan may be needed.

Although estimated PA prevalence slightly decreased in men starting in the cohorts born in the 1940s, it was found to consistently decrease in women starting in the cohorts born in approximately 1940. A possible reason for the obvious decrease of the cohort effect for women is the employment rate. The employment rate of women has continued to increase over the cohorts, and sedentary time has therefore increased as well. It has been reported in other countries that women with full-time sedentary jobs experienced less light-intensity and lifestyle-intensity activity than healthy non-workers [31], and also that sedentary behavior was particularly common among white-collar women [32]. A similar phenomenon may therefore be observed in Japan. According to a previous APC analysis, an increase in cohort effect for obesity prevalence in women in Japan began to emerge starting approximately in the 1960s [13], and the decrease in PA prevalence across the cohorts is thought to be related to this result. Furthermore, the cohort effect on mortality rate of cerebrovascular diseases and ischemic heart diseases was shown to have increased continuously in women starting in the cohorts born in ap- proximately 1960 [26], which might also be related to the cohort effects on decreased PA prevalence and the cohort effects on salt intake.

To conclude, in this study, we estimated cohort effects for each lifestyle behavior. The results from this study will be useful when interpreting results of APC analyses of lifestyle-related diseases in the future. Men showed higher estimated smoking and drinking prevalence in every age, period, and cohort, and a preventive approach to smoking and drinking is still required, particularly for men. On the other hand, for women, estimated PA prevalence clearly decreased over the cohorts, meaning that greater public awareness of insufficient PA is required in more recently born cohorts. Finally, estimated salt intake increased in recently born cohorts for both men and women, particularly for men. In light of the finding that the proportion of energy intake from fat has continuously increased for both men and women [13], changes in dietary habits are required for both genders.

\section{CONFLICT OF INTEREST}

The author has no conflicts of interest associated with the material presented in this paper.

\section{FUNDING}

None.

\section{ACKNOWLEDGEMENTS}

None.

\section{AUTHOR CONTRIBUTIONS}

\author{
All work was done by TO.
}

\section{ORCID}

Tasuku Okui https://orcid.org/0000-0001-5098-8502

\section{REFERENCES}

1. Statistics of Japan. The patient survey [cited 2020 Apr 17]. Available from: https://www.e-stat.go.jp/stat-search/files?pa ge $=1$ \&toukei $=00450022 \&$ tstat $=000001031167$ (Japanese). 
2. Ministry of Health, Labour and Welfare of Japan. Overview of national medical expenses 2017 [cited 2020 Apr 17]. Available from: https:/www.mhlw.go.jp/toukei/saikin/hw/k-iryohi/17/ index.html (Japanese).

3. Haneda M, Noda M, Origasa H, Noto H, Yabe D, Fujita Y, et al. Japanese clinical practice guideline for diabetes 2016. Diabetol Int 2018;9(1):1-45.

4. Kinoshita M, Yokote $K$, Arai $H$, lida M, Ishigaki Y, Ishibashi S, et al. Japan Atherosclerosis Society (JAS) guidelines for prevention of atherosclerotic cardiovascular diseases 2017. J Atheroscler Thromb 2018;25(9):846-984.

5. Shimazu T, Kuriyama S, Hozawa A, Ohmori K, Sato Y, Nakaya N, et al. Dietary patterns and cardiovascular disease mortality in Japan: a prospective cohort study. Int J Epidemiol 2007;36(3): 600-609.

6. Kang YJ, Wang HW, Cheon SY, Lee HJ, Hwang KM, Yoon HS. Associations of obesity and dyslipidemia with intake of sodium, fat, and sugar among Koreans: a qualitative systematic review. Clin Nutr Res 2016;5(4):290-304.

7. Strazzullo P, D'Elia L, Kandala NB, Cappuccio FP. Salt intake, stroke, and cardiovascular disease: meta-analysis of prospective studies. BMJ 2009;339:b4567

8. Ministry of Health, Labour and Welfare of Japan. Overview of the results of the National Health and Nutrition Survey in Japan 2017 [cited 2020 Apr 17]. Available from: https://www. mhlw.go.jp/content/10904750/000351576.pdf (Japanese).

9. Tanaka S. Status of physical activity in Japanese adults and children. Ann Hum Biol 2019;46(4):305-310.

10. Smith TR, Wakefield J. A review and comparison of age-period-cohort models for cancer incidence. Stat Sci 2016;31(4): 591-610.

11. Ma E, Iso H, Takahashi H, Yamagishi K, Tanigawa T. Age-periodcohort analysis of mortality due to ischemic heart disease in Japan, 1955 to 2000. Circ J 2008;72(6):966-972.

12. Ito $\mathrm{Y}$, loka A, Nakayama T, Tsukuma H, Nakamura T. Comparison of trends in cancer incidence and mortality in Osaka, Japan, using an age-period-cohort model. Asian Pac J Cancer Prev 2011;12(4):879-888.

13. Yamakita M, Uchida H, Kawamura K, Homma T, Odagiri Y. Effects of age, period, and cohort on the trends in obesity rate and energy intake ratio from fat in Japanese adults. Nihon Koshu Eisei Zasshi 2014;61(8):371-384 (Japanese).

14. Statistics of Japan. The National Health and Nutrition Survey in Japan 2017 [cited 2020 Apr 17]. Available from: https:// www.e-stat.go.jp/stat-search/files?page $=1$ \&toukei $=004501$ 71\&tstat $=000001041744$ (Japanese).

15. National Institute of Health and Nutrition. The National Health and Nutrition Survey [cited $2020 \mathrm{Jul}$ 3]. Available from: https:// www.nibiohn.go.jp/eiken/kenkounippon21/eiyouchousa/ keinen_henka_eiyou.html (Japanese).

16. Saito A, Imai S, Htun NC, Okada E, Yoshita K, Yoshiike N, et al. The trends in total energy, macronutrients and sodium intake among Japanese: findings from the 1995-2016 National Health and Nutrition Survey. Br J Nutr 2018;120(4):424-434.

17. Naing NN. Easy way to learn standardization: direct and indirect methods. Malays J Med Sci 2000;7(1):10-15.

18. Statistics of Japan. The vital statistics [cited 2020 Apr 17]. Available from: https://www.e-stat.go.jp/stat-search/files?page $=1$ \&layout $=$ datalist $\&$ touke $=00450011 \&$ tstat $=000001028897 \&$ cycle $=7 \&$ tclass $1=000001053058 \&$ tclass $2=000001053061 \& t$ class3 $=000001053072$ (Japanese).

19. Kwok MK, Wong IO, Schooling CM. Age-period-cohort projection of trends in blood pressure and body mass index in children and adolescents in Hong Kong. BMC Pediatr 2020; 20(1):43

20. Schmid VJ, Held L. Bayesian age-period-cohort modeling and prediction-BAMP. J Stat Softw 2007;21(8):1-15.

21. Lee HA, Park H. Trends in ischemic heart disease mortality in Korea, 1985-2009: an age-period-cohort analysis. J Prev Med Public Health 2012;45(5):323-328.

22. Peng $Y$, Wang Z. Prevalence of three lifestyle factors among Australian adults from 2004 to 2018: an age-period-cohort analysis. Eur J Public Health 2020;30(4):827-832.

23. Stan Development Team. RStan: the R interface to Stan. R package version 2.19.2 [cited $2020 \mathrm{Apr}$ 17]. Available from: http:// mc-stan.org/.

24. Miura K, Nagai M, Ohkubo T. Epidemiology of hypertension in Japan: where are we now? Circ J 2013;77(9):2226-2231.

25. Funatogawa I, Funatogawa T, Yano E. Trends in smoking and lung cancer mortality in Japan, by birth cohort, 1949-2010. Bull World Health Organ 2013;91(5):332-340.

26. Okui T. Age-period-cohort analysis of cardiovascular disease mortality in Japan, 1995-2018. J Prev Med Public Health 2020; 53(3):198-204.

27. Fukuda Y, Nakamura K, Takano T. Socioeconomic pattern of smoking in Japan: income inequality and gender and age differences. Ann Epidemiol 2005;15(5):365-372.

28. Temple MT, Fillmore KM, Hartka E, Johnstone B, Leino EV, Motoyoshi M. A meta-analysis of change in marital and employment status as predictors of alcohol consumption on a typical 
occasion. Br J Addict 1991;86(10):1269-1281.

29. Moore AA, Gould R, Reuben DB, Greendale GA, Carter MK, Zhou $\mathrm{K}$, et al. Longitudinal patterns and predictors of alcohol consumption in the United States. Am J Public Health 2005;95(3): 458-465.

30. Wendt S, Mohr C, Wang M, Haverly S. Proximal predictors of alcohol use among Japanese college students. Subst Use Misuse 2018;53(5):763-772.
31. Van Domelen DR, Koster A, Caserotti P, Brychta RJ, Chen KY, McClain JJ, et al. Employment and physical activity in the U.S. Am J Prev Med 2011;41(2):136-145.

32. van Dommelen $P$, Coffeng JK, van der Ploeg HP, van der Beek AJ, Boot CR, Hendriksen IJ. Objectively measured total and occupational sedentary time in three work settings. PLoS One 2016;11(3):e0149951. 